\title{
CONDIÇÕES AMBIENTAIS DO ESTUÁRIO DO RIO BOTAFOGO (ITAMARACÁ- PERNAMBUCO-BRASIL): CLOROFILA a E ALGUMAS VARIÁVEIS AMBIENTAIS.
}

Recebido em: julho/2013

Aceito em: agosto/2013

\author{
Amanda Yumi OTSUKA ${ }^{1}$ \\ Fernando Antônio do Nascimento FEITOSA ${ }^{1}$ \\ Manuel de Jesus FLORES MONTES ${ }^{1}$ \\ Marcos HONORATO DA SILVA ${ }^{1}$ \\ Rysoaurya Keyla TRAVASSOS ${ }^{1}$
}

\section{RESUMO}

Este trabalho teve o objetivo de caracterizar o estuário do rio Botafogo (Itamaracá-PE) a partir da análise da clorofila a e alguns parâmetros ambientais. Foram feitas coletas mensais, em três pontos de amostragem ao longo do estuário, no período de abril/07 a março/08, em diferentes estágios e em maré de sizígia. Foi utilizada a garrafa de Kitahara na camada superficial da água para a análise de biomassa, Secchi, salinidade, oxigênio dissolvido, DBO, nutrientes, material particulado em suspensão. A biomassa fitoplanctônica variou sazonalmente, com maiores concentrações no período chuvoso e em baixa-mar. Os valores em média estiveram abaixo de $20 \mathrm{mg} \cdot \mathrm{m}^{-3}$, e a fração menor que $20 \mu \mathrm{m}$ foi a que mais contribuiu para o ecossistema. A ACP mostrou uma correlação direta da clorofila com os nutrientes e inversa com a salinidade e oxigênio dissolvido. O ambiente dessa forma mostrou uma qualidade ambiental ainda satisfatória, porém em processo moderado de eutrofização.

Palavras chave: sazonalidade, biomassa fitoplanctônica, parâmetros hidrológicos, área costeira.

\section{ABSTRACT}

This work was aimed in characterizing the Rio Botafogo Estuary (Itamaracá-PE) based on the analysis of the chlorophyll a and some environmental parameters. It was performed monthly sampling in three different points throughout the estuary, during the period of April $7^{\text {th }}$ to March $8^{\text {th }}$ in different stages and in spring tides. The Kitahara bottle was utilized in the superficial waters in order to perform analysis of biomass, Secchi, salinity, dissolved oxygen, BDO, nutrients, particulate material in suspension. The phytoplanktonic biomass varied seasonally with the highest concentrations in the raining season and during the low tide. The mean values were below $20 \mathrm{mg} \cdot \mathrm{m}^{-3}$, and the fraction under 20 $\mathrm{mm}$ was the most contributing to the ecosystem. The ACP showed a direct correlation between the chlorophyll and the nutrients, and an inverse correlation between salinity and dissolved oxygen. The environment showed a still suitable environmental quality, but in a moderated eutrofization process.

Key words: Seasonality, phytoplanktonic biomass, hydrological parameters, coastal area.

\section{INTRODUÇÃO}

Estuário se refere a um corpo d'água semifechado, em que a salinidade é intermediária entre água salgada e doce, e possui como regulador físico importante à ação da maré. O mesmo está entre os ecossistemas mais férteis do mundo. (ODUM et al. 2007)

Por se tratarem de ambientes que normalmente possuem uma elevada produção primária, são consideradas áreas de grande importância ecológica como também econômica, pois constituem áreas quase sempre eutróficas, com expressiva atividade fotossintética. Por esta 
OTSUKA, A. Y. Condições Ambientais do estuário do rio Botafogo (Itamaracá-Pernambuco-Brasil): clorofila a e algumas variáveis ambientais.

razão, funcionam como verdadeiros berçários naturais de diversos organismos, o que torna o estudo desse ambiente bastante relevante. (PASSAVANTE et al., 1988)

Dentre os produtores primários do ecossistema estuarino, o fitoplâncton desempenha um papel bastante significativo na téia trófica, pois o mesmo além de representar o primeiro elo da mesma, os organismos que o compõem são considerados excelentes bioindicadores da qualidade da água. (PASSAVANTE et al., 2003)

Segundo Noriega et al. (2005) os estudos sobre biomassa fitoplanctônica (clorofila a) são relevantes, devido à importância deste pigmento na fotossíntese através da qual é processada a matéria orgânica e liberado o oxigênio. Além disso, o estudo quantitativo do fitoplâncton oferece valiosas informações sobre a potencialidade produtiva de uma determinada área e sua qualidade ambiental.

Com a finalidade de conhecer melhor este ambiente, trabalhos pretéritos em diversas áreas da oceanografia, como ecologia e taxonomia de plâncton, bentos e hidrologia, foram realizadas com o objetivo de caracterizar a área: por Cavalcanti (1979), Paranaguá et al. (1979), Soares (1979), Eskinazi-Leça et al. (1980), Cavalcanti et al. (1981), Passavante (1981), Eskinazi-Leça (1984), Passavante e Koening (1984), Macedo et al. (1987/89), Passavante (1987/89), Flores Montes et al. (1998), Santos-Fernandes et al. (1998), SantosFernandes et al. (2000), Passavante et al. (2003), Moura e Passavante (2003), Lacerda et al. (2004), Silva et al. (2004), Leão et al. (2007), Leão et al. (2008), Melo et al. (2008), Santos et al. $(2008 ; 2009)$.

O presente trabalho teve o objetivo de avaliar as condições ambientais do estuário do rio Botafogo (Itamaracá-PE) através da biomassa fitoplanctônica (clorofila a) com os parâmetros hidrológicos.

\section{DESCRIÇÃO DE ÁREA}

A ilha de Itamaracá está localizada no estado de PE, cerca de $50 \mathrm{~km}$ ao norte da cidade do Recife. Situa-se entre as latitudes $7^{\circ} 34^{\prime} 00^{\prime \prime} \mathrm{S}$ e $7^{\circ} 55^{\prime} 16^{\prime \prime} \mathrm{S}$ e entre as longitudes $34^{\circ} 48^{\prime} 48^{\prime \prime} \mathrm{W}$ e $34^{\circ} 52^{\prime} 24^{\prime \prime}$ W. O Canal de Santa Cruz é um braço de mar que contorna a Ilha de Itamaracá, separando-a do continente. Diversos cursos d'água desembocam no Canal de Santa Cruz, dentre eles se destaca o rio Botafogo, o maior rio que deságua neste canal, com uma extensão de aproximadamente $50 \mathrm{~km}$, formado pela junção de diversos rios, destacando-se o Catucá, Itapirema e Arataca. A bacia hidrográfica do rio Botafogo faz parte do sistema Botafogo, que faz o abastecimento de água potável para região metropolitana do Recife (MACEDO, 1974). A vazão deste rio (4.460 $\mathrm{Ls}^{-1}$ ) é insuficiente para a captação d'água das indústrias (químicas, açúcar e álcool) ali instaladas, assim como para efeito de diluição dos efluentes líquidos lançados, acarretando maior contribuição de agentes poluentes no Canal de Santa Cruz (MACEDO, 1974; SILVA, 2004). Desta forma, a carga de poluentes do estuário do rio Botafogo é bastante elevada, provocando um acentuado desequilíbrio neste ecossistema. (MACEDO et al. 2000; CPRH 2004) (Fig. 1).

O clima da área segundo a classificação de Köppen é do tipo As': clima quente e úmido. O período de estiagem ocorre entre os meses de setembro a fevereiro, e o período chuvoso entre março a agosto. A precipitação média é superior a $100 \mathrm{~mm} / \mathrm{m}$ podendo atingir $400 \mathrm{~mm} / \mathrm{m}$. A taxa de evaporação é inferior a de precipitação, havendo um balanço anual positivo. A temperatura máxima chega a $34^{\circ} \mathrm{C}$, e a mínima $20^{\circ} \mathrm{C}$. (SILVA, 2004; TORRES; MACHADO, 2011)

De acordo com a CPRH (2001) e Moura et al.(2011), revelaram que no período de 1996 a 2011 ocorreu um desflorestamento no manguezal, principalmente para dar espaço à instalação de fazenda de camarão. O aumento da atividade de carcinicultura nesse período, motivada por benefício econômico, atingiu em torno de 331\%. No estuário do rio Botafogo, dois grandes projetos de carcinicultura se encontram em atividade: a Maricultura Netuno e a Atapuz Aquicultura. 


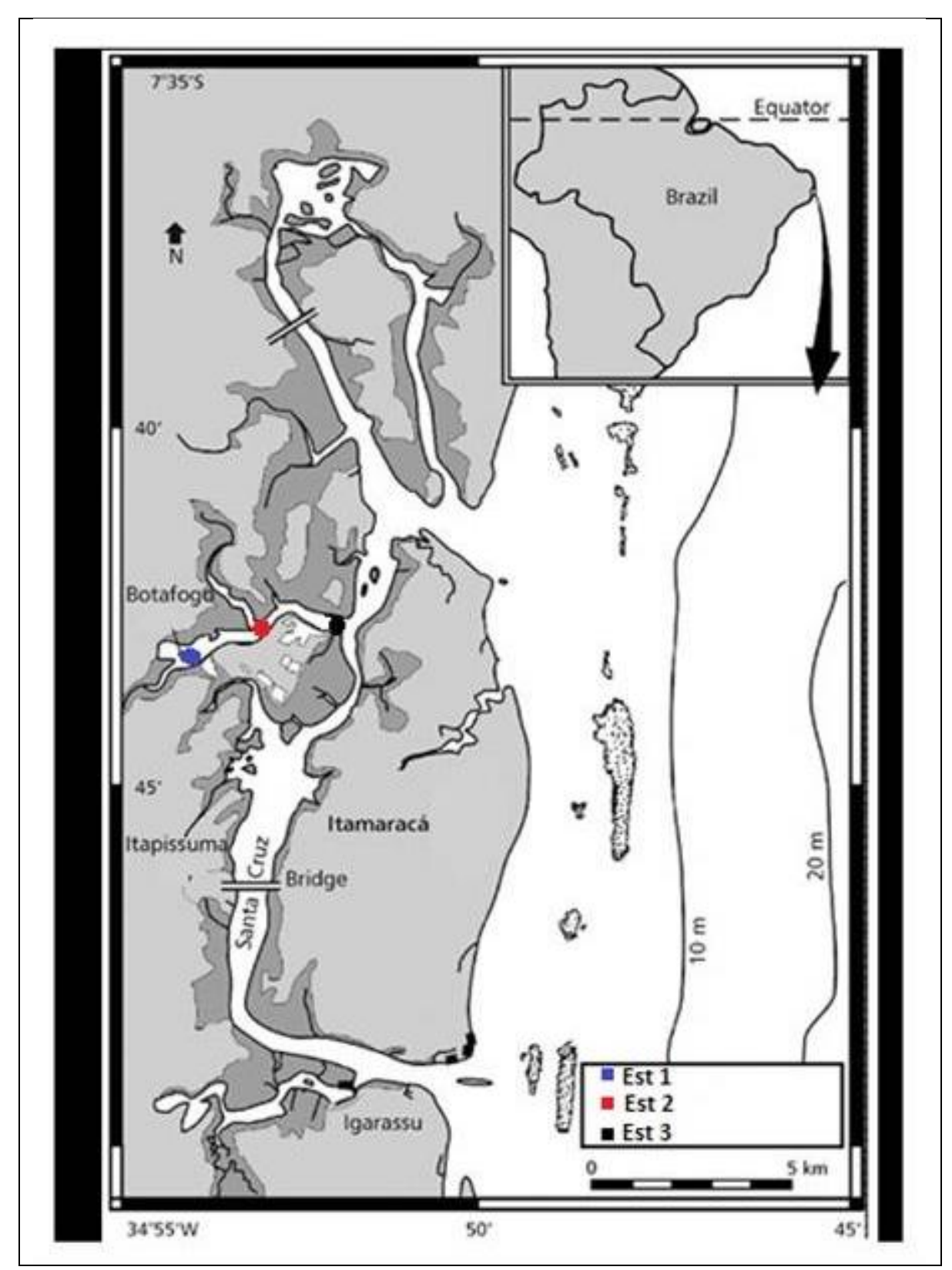

Figura 1 - Área de estudo. Estações de coleta no estuário do rio Botafogo/PE. Modificado de Lacerda et al (2004).

\section{MATERIAL E MÉTODOS}

As coletas foram realizadas mensalmente, no período de abril/2007 a março/2008, com o intuito de abranger os diferentes períodos (chuvoso e estiagem) nos estágios de baixa-mar (BM) e preamar (PM) de um mesmo dia, em marés de sizígia, em estações fixas de amostragem na zona estuarina do rio Botafogo: Est 1 porção superior; Est 2 porção intermediária e Est 3 porção inferior. As amostras hidrológicas e biológicas foram realizadas utilizando a garrafa Kitahara na camada superficial da água.

\section{Análise dos dados abióticos}

Dados pluviométricos foram obtidos através do LAMEPE/ITEP. A altura da maré foi baseada na Tábua de Maré (DHN).

As análises hidrológicas foram realizadas no Laboratório de Química do Departamento de Oceanografia da UFPE. A transparência e temperatura da água foram medidas in situ através de um disco de Secchi com cabo graduado em centímetros e termômetro comum de mercúrio, respectivamente; a profundidade local foi determinada através de uma ecossonda digital da 
OTSUKA, A. Y. Condições Ambientais do estuário do rio Botafogo (Itamaracá-Pernambuco-Brasil): clorofila a e algumas variáveis ambientais.

marca LCD; para a salinidade utilizou-se o método de Mohr-Knudsen e o oxigênio dissolvido pelo método de Winkler, ambos descritos em Strickland e Parsons (1972); taxa de saturação do oxigênio dissolvido utilizou-se a "International Oceanographic Tables" (UNESCO, 1973) correlacionado os valores de temperatura e salinidade; para a demanda bioquímica utilizou-se a metodologia descrita por Standard Methods (APHA, 1997). O pH foi determinado por um pHmetro Hanna Instruments; para os sais nutrientes (amônia, nitrito, nitrato e fosfato) o método de Strickland e Parsons (1972), e silicato, pelo Grasshoff et al. (1983); para o material particulado em suspensão total, conforme o método americano utilizado pelo Woods Hole Institution descrito por Melo et al. (1975).

\section{Análise dos dados bióticos}

A biomassa fitoplanctônica total e fracionada foi quantificada através da concentração de clorofila $a$, utilizando o método espectrofotométrico da UNESCO (1966) após extração em acetona a $90 \%$ por 24 horas. As leituras foram obtidas no espectrofotômetro BIOCHROM LIBRA $\mathrm{S} 6$ e os resultados expressos em $\mathrm{mg} \cdot \mathrm{m}^{-3}$. Para o fracionamento utilizou-se um copo de PVC com malha de náilon de $20 \mu \mathrm{m}$ para separar as frações menores do que $20 \mu \mathrm{m}$ (picofitoplâncton e nanofitoplâncton) e maior que $20 \mu \mathrm{m}$ (microfitoplâncton) (Platt et al. 1983)

\section{Análise estatística}

Foi realizado o teste de kruskal-wallis para verificar a existência de diferenças entre os parâmetros estudados em função dos fatores de sazonalidade, e anova um critério para espacialidade e diferentes estágios de maré, sendo considerados significativos os valores < 0,05 .

A análise multivariada dos resultados foi realizada através da análise dos componentes principais, com base na matriz de correlação momento-produto de Pearson. Em seguida, foram extraídos o autovetor e o autovalor dos dois principais componentes. Os cálculos foram realizados utilizando o programa computacional NTSYS (Numerical Taxonomy and Multivariate Analisys System) da Exeter Software, New York - EUA.

\section{RESULTADOS}

\section{- Pluviometria}

Durante o período estudado o total de chuvas mensais foi de $1586,6 \mathrm{~mm}$ ficando ligeiramente abaixo da média histórica mensal (1991/2008) que foi de $1774 \mathrm{~mm}$. No período estudado, foi observado um valor máximo de $370,9 \mathrm{~mm}$, encontrado em jul/07 e o mínimo de $8,5 \mathrm{~mm}$, em nov/07. Houve uma variação sazonal significativa $(p=0,00)$ (Fig. 2) (Tab. 2).

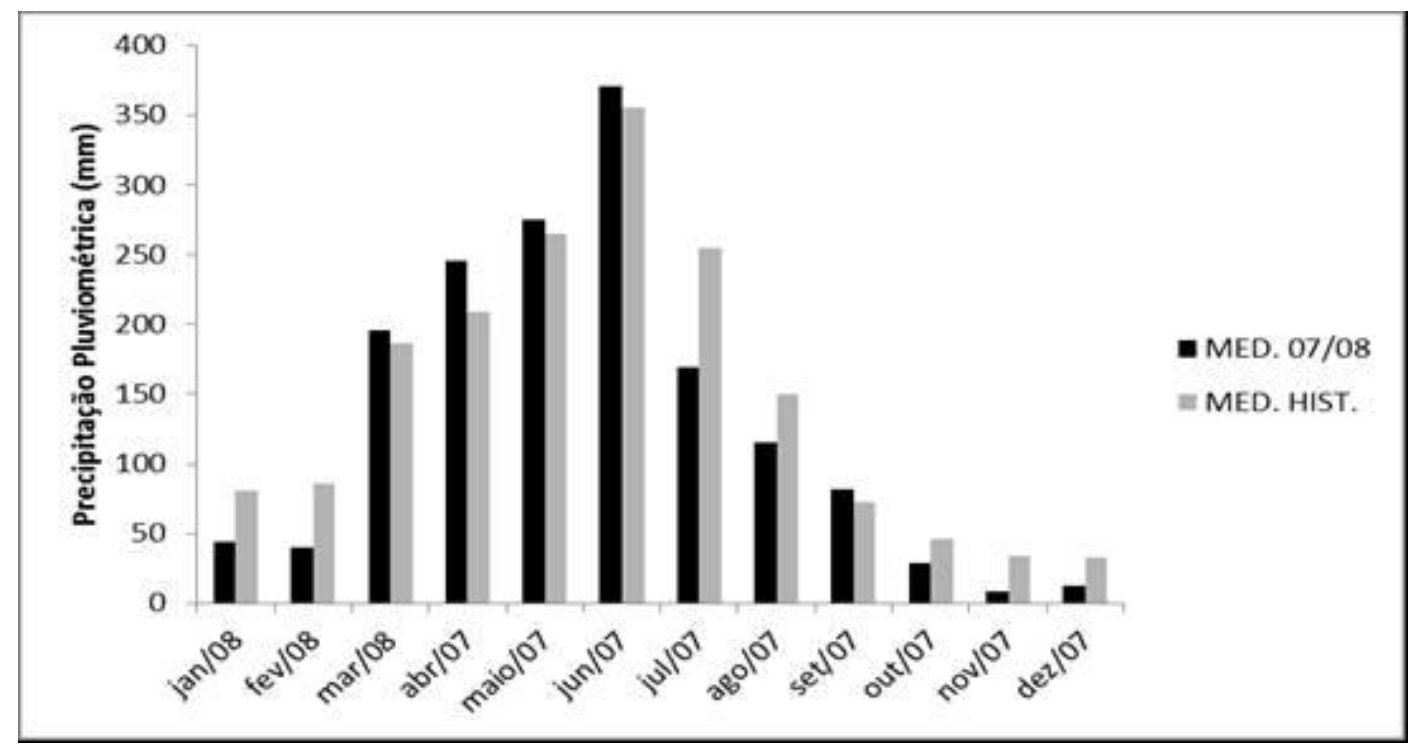

Fonte: LAMEP/ITEP

Figura 2 - Dados pluviométricos de Itamaracá e a média mensal histórica. 


\section{- Maré}

A maré variou significativamente com relação a sua altura $(p=0,00)$. A altura variou entre $0,0-2,5 \mathrm{~m}$, caracterizando como mesomaré. Com regime semi-diurno. (Tab. 2).

\section{- Temperatura}

A temperatura da água apresentou pequenas variações oscilando, em sua maioria, entre 25 a $30^{\circ} \mathrm{C}$. Somente na Est 3, em preamar, que foi obtido um valor maior que a média, $39,8^{\circ} \mathrm{C}$, no mês de março/08. No período de estiagem, os valores variaram entre 21,5 a $31,1{ }^{\circ} \mathrm{C}$ (Tab. 2).

\section{- Secchi}

A transparência variou sazonalmente $(p=0,00)$. Os valores variaram de $0,3-2,4 m$, na Est 2, em baixar mar e Est 3, na preamar, respectivamente (Tab. 2).

\section{- Profundidade}

Os valores de profundidade variaram entre $3 \mathrm{~m}$ (Est 3 em baixa-mar) a 8,3 m (Est 2 em preamar) no período chuvoso e no período de estiagem os valores variaram entre $0,8 \mathrm{~m}$ (Est 1 na baixa-mar) a 8,7 m (Est 2 na preamar). Este parâmetro teve diferença significativa com relação à altura de maré $(p=0,02)$ e sazonalidade $(p=0,00)$ (Tab. 2$)$.

\section{- Salinidade}

A salinidade teve uma variação tanto sazonal $(p=0,04)$ quanto em relação a diferentes estágios de maré $(p=0,00)$. Os maiores valores foram observados na preamar. 0 máximo foi de 37,94, no mês de mar/08 na Est 3 e o mínimo de 4,73, no mês de jul/07 na Est 1 . Com relação à espacialidade, as Est 1 e 2 foram iguais $(p=0,61)$ e estas foram diferentes da Est 3 $(p=0,00)($ Fig. 4) (Tab. 2).

\section{- Oxigênio dissolvido (O.D)}

As concentrações de oxigênio dissolvido variaram significativamente de acordo com a altura de maré $(p=0,03)$. As médias de oxigênio dissolvido na baixa-mar foram de $4,07 \mathrm{ml} / \mathrm{L}^{-1}$ e na preamar de $4,52 \mathrm{ml} / \mathrm{L}^{-1}$. A maior concentração foi de $6,5 \mathrm{ml} / \mathrm{L}^{-1}$, na Est $3 \mathrm{em}$ ago/07, na preamar, e a menor foi de 1,99 ml/ $\mathrm{L}^{-1}$, na Est 2 em julh/07, na baixa-mar. (Fig. 3). 


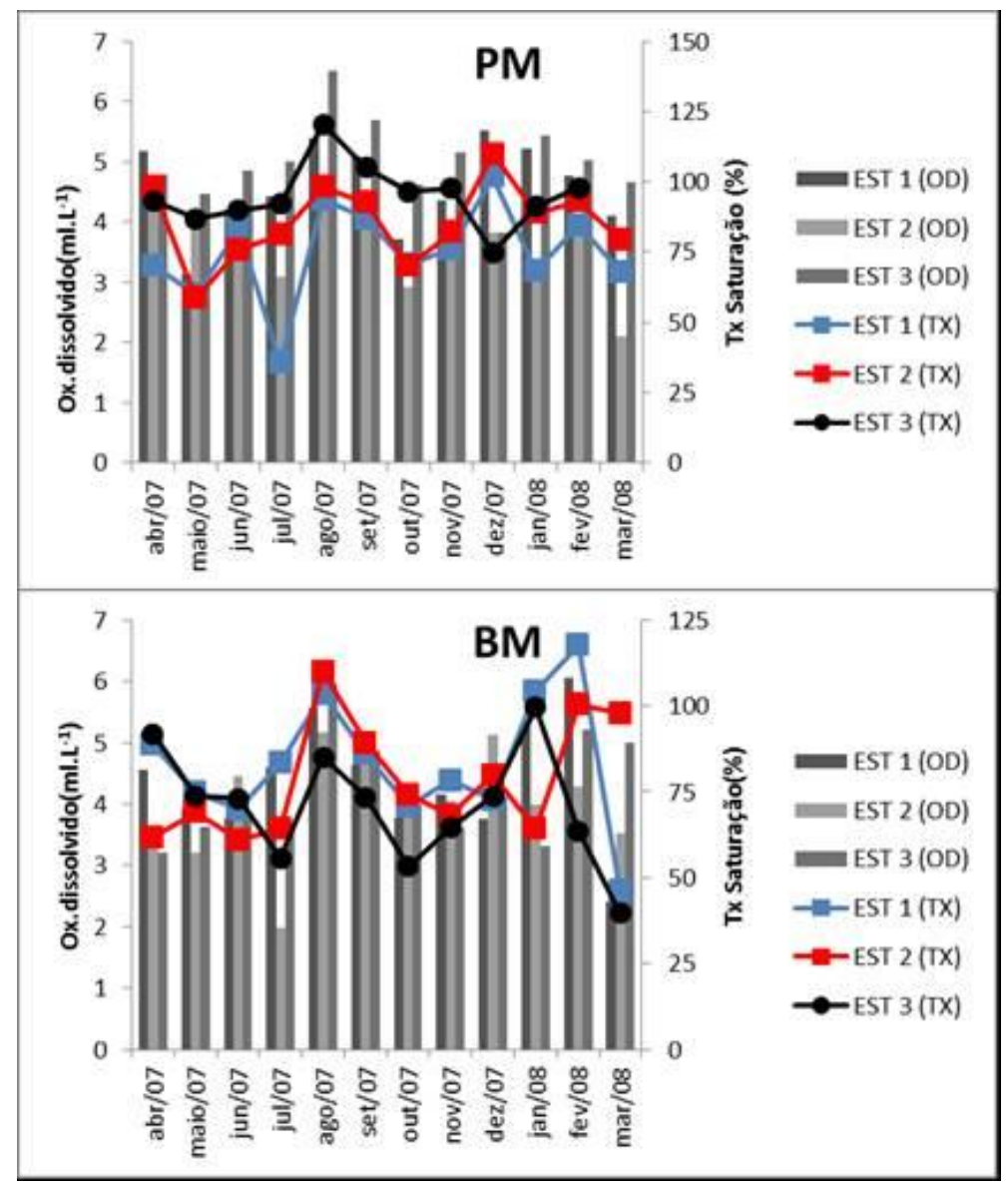

Figura 3 - Oxigênio dissolvido e taxa de saturação, em baixa-mar (BM) e preamar (PM).

\section{- Demanda Bioquímica do Oxigênio (DBO)}

Os valores de demanda bioquímica do oxigênio variaram tanto sazonalmente $(p=0,01)$ quanto em relação à altura de maré $(p=0,02)$. As médias de $D B O$ no período chuvoso foram de $2,36 \mathrm{mg} \cdot \mathrm{L}^{-1}$ na baixa-mar e de $1,99 \mathrm{mg} \cdot \mathrm{L}^{-1}$ na preamar. No período de estiagem, as médias foram de $1,54 \mathrm{mg} \cdot \mathrm{L}^{-1}$ na baixa-mar e $0,84 \mathrm{mg} \cdot \mathrm{L}^{-1}$ na preamar (Tab. 2 ).

- pH

O ambiente se manteve alcalino. No período chuvoso foi observado uma média de $7,98 \mathrm{com}$ valores variando de 6,92 a 8,68 , e no período de estiagem a média foi de 8,15 , os valores variaram entre 7,35 a 8,44 . Houve diferença significativa com relação à maré $(p=0,00)$ e sazonalidade $(p=0,06)$ (Tab. 2$)$.

\section{- Material Particulado em Suspensão (MPS)}

O MPS teve uma variação com relação aos diferentes estágios de maré $(p=0,00)$. As concentrações foram mais elevadas na preamar, com o máximo de $46,6 \mathrm{mg} \cdot \mathrm{L}^{-1}$ na Est 3 , em abr/07 e mínimo de 5,8 mg. $\mathrm{L}^{-1}$ na mesma estação, em dez/07. Na baixa-mar, os valores mínimos e máximos foram de $45 \mathrm{mg} \cdot \mathrm{L}^{-1}$ na Est 3, em mar/08 e $2 \mathrm{mg} \cdot \mathrm{L}^{-1}$ na Est 3, em dez/08, respectivamente (Fig. 4) (Tab. 2). 


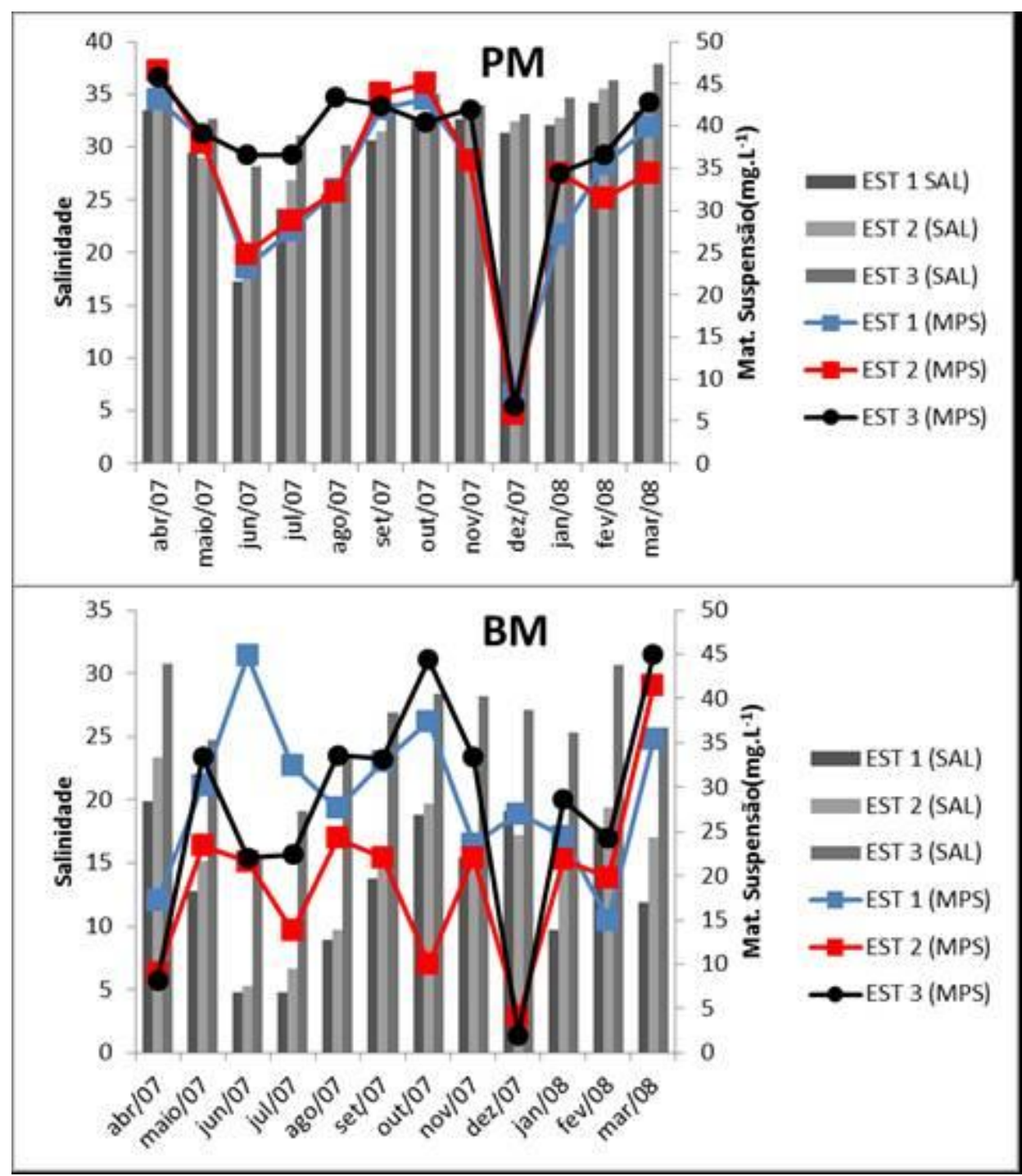

Figura 4 - Salinidade e material particulado em suspensão, em preamar (PM) e baixa-mar (BM)

\section{- Amônia $\left(\mathrm{NH}_{3}\right)$}

$\mathrm{O} \mathrm{NH}_{3}$ variou sazonalmente $(p=0,00)$. As maiores concentrações a foram encontradas no período chuvoso. Os valores variaram de não detectáveis a 2,89 $\mu \mathrm{mol}$. $\mathrm{L}^{-1}$, na Est $1 \mathrm{em}$ mar/08, na baixa-mar. E no período de estiagem, variaram de não detectáveis a $0,17 \mu \mathrm{mol} . \mathrm{L}^{-1}$ na Est 2 em out/07, na baixa-mar (Fig. 7) (Tab. 2).

\section{- Nitrito $\left(\mathrm{NO}_{2}\right)$}

O nitrito variou de valores não detectáveis a $0,67 \mu \mathrm{mol} . \mathrm{L}^{-1}$ no período chuvoso, na Est 2 preamar e E1 na baixa-mar, respectivamente. No período de estiagem, a concentração variou de valores indetectáveis a $0,28 \mu \mathrm{mol} . \mathrm{L}^{-1}$ na Est1 na preamar e baixa-mar, respectivamente. Observou-se uma variação significativa para altura de maré $(p=0,00)$ e sazonalidade $(p=0,01)$. As Est 2 e 3 se mostraram iguais $(p=0,06)$ e as mesmas foram diferentes da Est $1(p=0,03)$ (Fig. 5) (Tab. 2).

\section{- Nitrato $\left(\mathrm{NO}_{3}\right)$}

Os maiores valores de $\mathrm{NO}_{3}$ foram encontrados no período chuvoso, variando entre 0,12 umol. $\mathrm{L}^{-1}$ (Est 3, ago/07, preamar) a 34,94 $\mu \mathrm{mol} . \mathrm{L}^{-1}$ (Est 1, julh/07, baixa-mar) e no período de estiagem variou entre $0,22 \mu \mathrm{mol} . \mathrm{L}^{-1}$ (Est 3, set/08, baixa-mar) a 14,70 $\mu \mathrm{mol}^{-1} \mathrm{~L}^{-1}$ (Est 1 , set/08, baixa-mar). Este parâmetro teve diferenças significativas com relação à altura de maré $(p=0,00)$, sazonalidade $(p=0,04)$. As Est 2 e 3 mostraram semelhantes $(p=0,60)$ e estas foram 
OTSUKA, A. Y. Condições Ambientais do estuário do rio Botafogo (Itamaracá-Pernambuco-Brasil): clorofila a e algumas variáveis ambientais.

$\begin{array}{llllllll}\text { diferentes } & \text { da } & \text { Est } & 1 & (p=0,00) & \text { (Fig. } & 5) & \text { (Tab. }\end{array}$

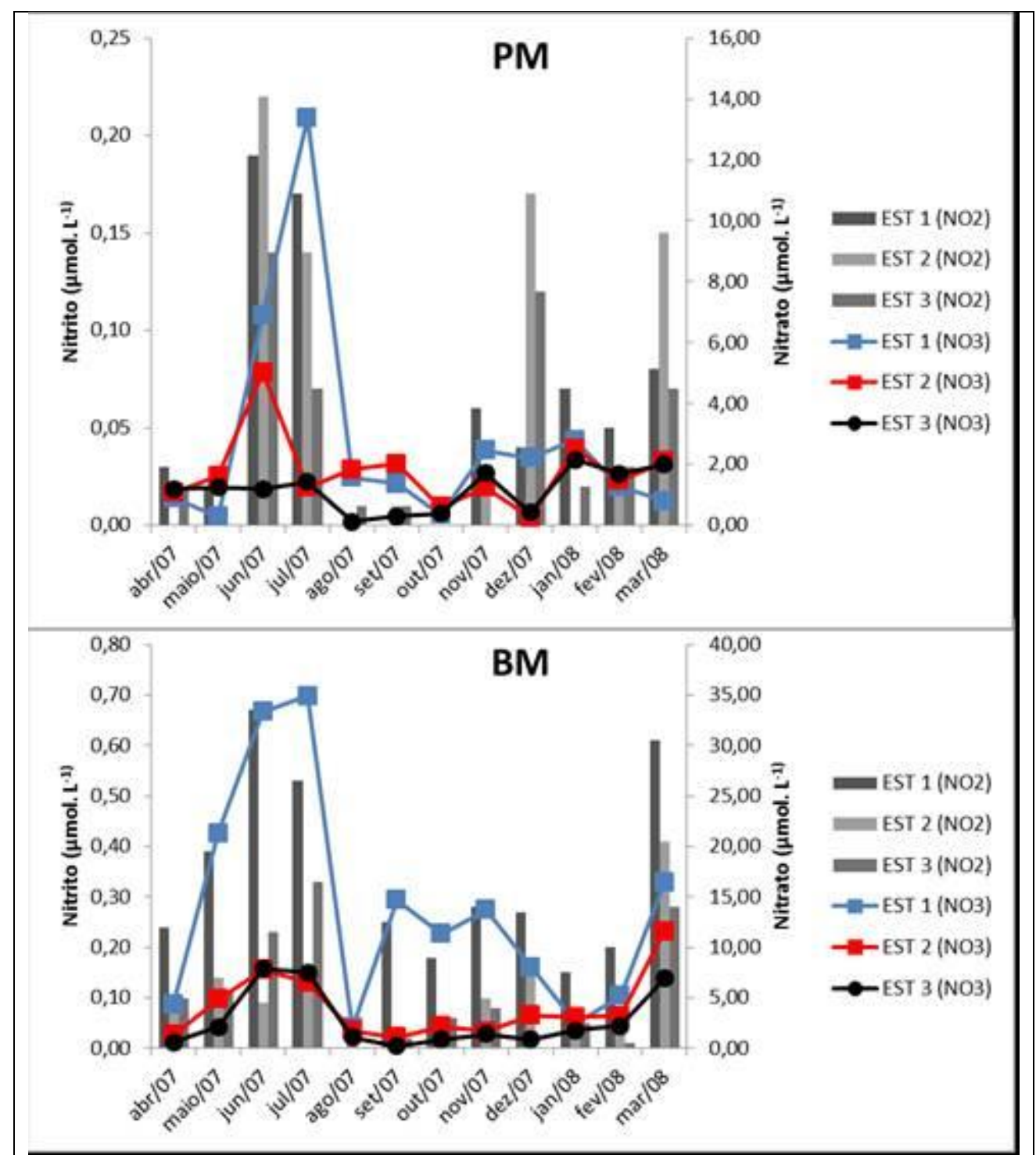

Figura 5 - Variação dos valores de $\mathrm{NO}_{2}$ e $\mathrm{NO}_{3}$, em preamar (PM) e baixa-mar (BM)

\section{- Silicato $\left(\mathrm{SiO}_{2}\right)$}

O silicato variou de acordo com os diferentes estágios de maré $(p=0,00)$. A média para baixa-mar foi de $86,93 \mu \mathrm{mol}$. $\mathrm{L}^{-1}$ e para preamar $19,63 \mu \mathrm{mol}$. $\mathrm{L}^{-1}$. Foi observado um pico de $\mathrm{SiO}_{2}$ na Est 2 em dez/07 $\left(221,12 \mu \mathrm{mol} . \mathrm{L}^{-1}\right)$ e em mar/08 ( 178,07 $\mu \mathrm{mol}$. $\left.\mathrm{L}^{-1}\right)$. As Est 1 e 2 foram semelhantes $(p=0,66)$ e estas foram diferentes da Est $3(p=0,01)$ (Fig. 6) (Tab. 2). 


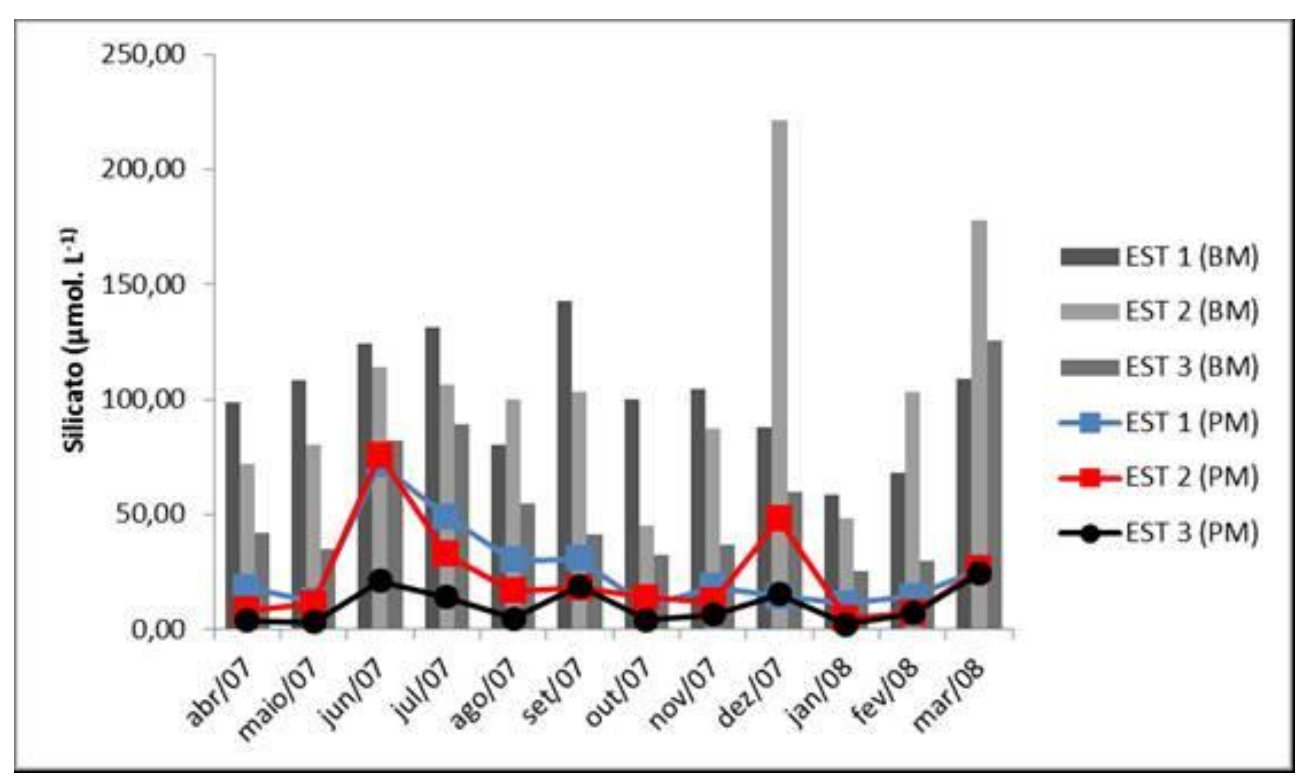

Figura 6 - Dados obtidos para $\mathrm{SiO}_{2}$, em preamar (PM) e baixa-mar (BM)

\section{- Fosfato $\left(\mathrm{PO}_{4}\right)$}

O fosfato variou sazonalmente $(p=0,00)$ e em relação às diferentes alturas de maré $(p=0,00)$. Os valores oscilaram de não detectáveis a $1,74 \mu \mathrm{mol}$. $\mathrm{L}^{-1}$ (Est 3 , julh/07, na baixamar) no período chuvoso e no período de estiagem variaram de valores não detectáveis a 1,38 $\mu \mathrm{mol} . \mathrm{L}^{-1}$ (Est 1, dez/07, na baixa-mar) (Fig. 7) (Tab. 2).

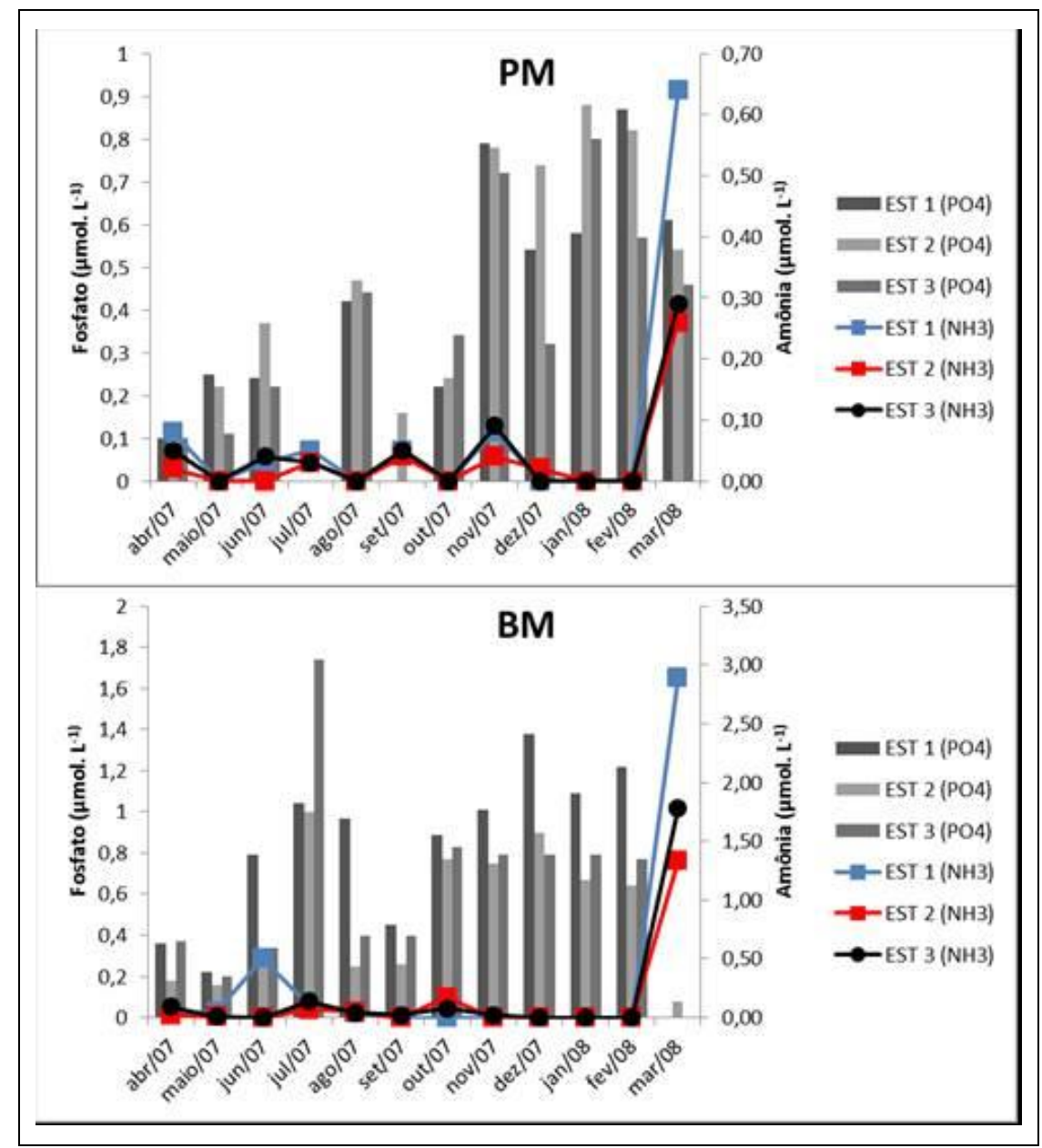

Figura 7 - Variação dos valores de $\mathrm{PO}_{4}$ e $\mathrm{NH}_{3}$, em preamar (PM) 
OTSUKA, A. Y. Condições Ambientais do estuário do rio Botafogo (Itamaracá-Pernambuco-Brasil): clorofila a e algumas variáveis ambientais.

\section{- Clorofila a}

A biomassa fitoplanctônica variou sazonalmente $(p=0,00)$. As maiores concentrações foram observadas no período chuvoso e em baixa-mar. Os valores de clorofila a variaram entre $2,15 \mathrm{mg} \cdot \mathrm{m}^{-3}$ na Est 3, na preamar de jan/08 a 59,75 mg.m ${ }^{-3}$ na mesma estação em jul/07 no período de baixa-mar.

A partir do fracionamento foi observado que a concentração dos organismos menores do que $20 \mu \mathrm{m}$ (picofitoplâncton e nanofitoplâncton) foi muito maior em relação aos maiores que 20 $\mu \mathrm{m}$ (microfitoplâncton) (Fig. 8 e 9) (Tab. 2).

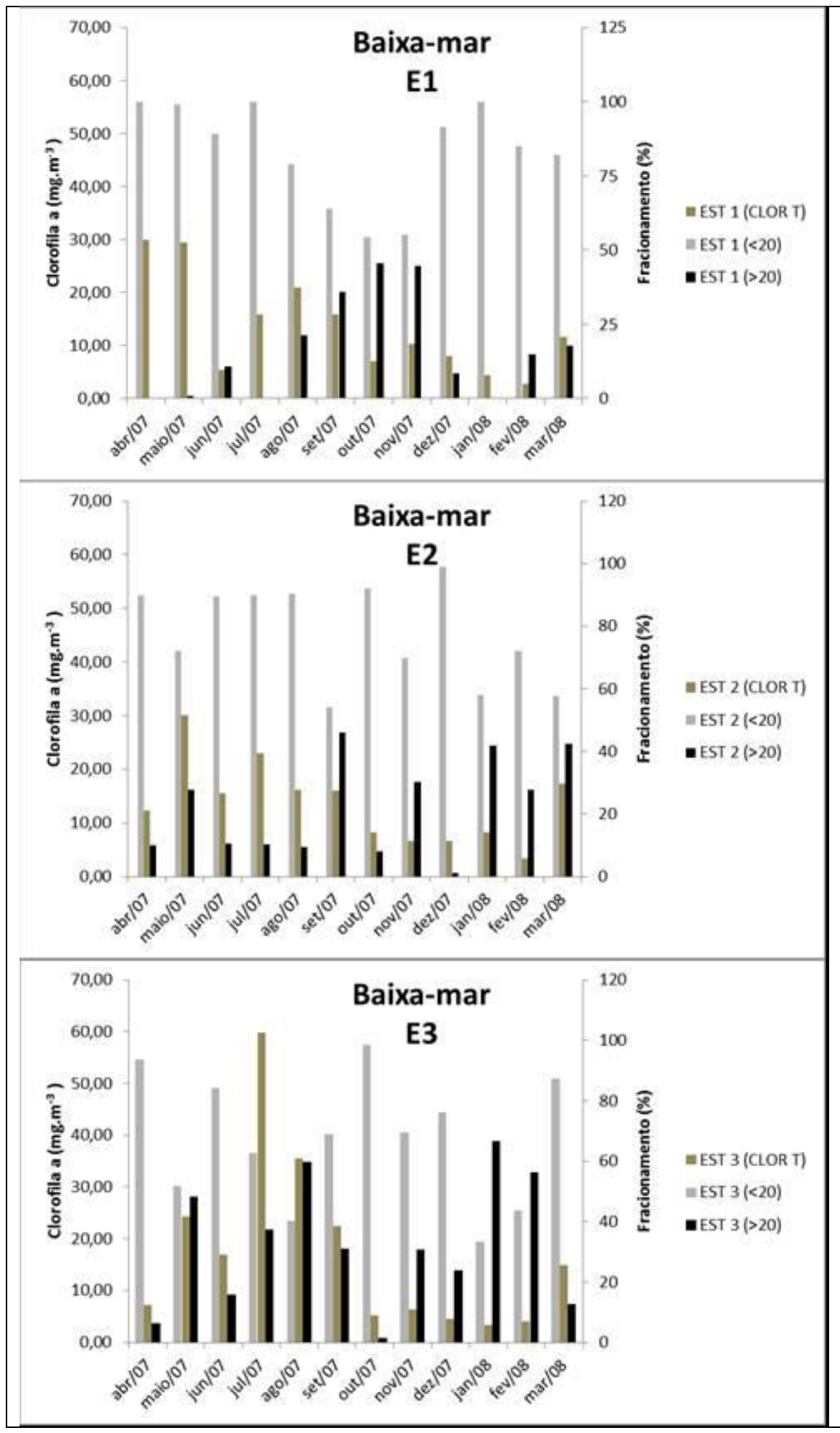

Figura 8 - Clorofila a em cada estação, em baixa-mar (BM) 


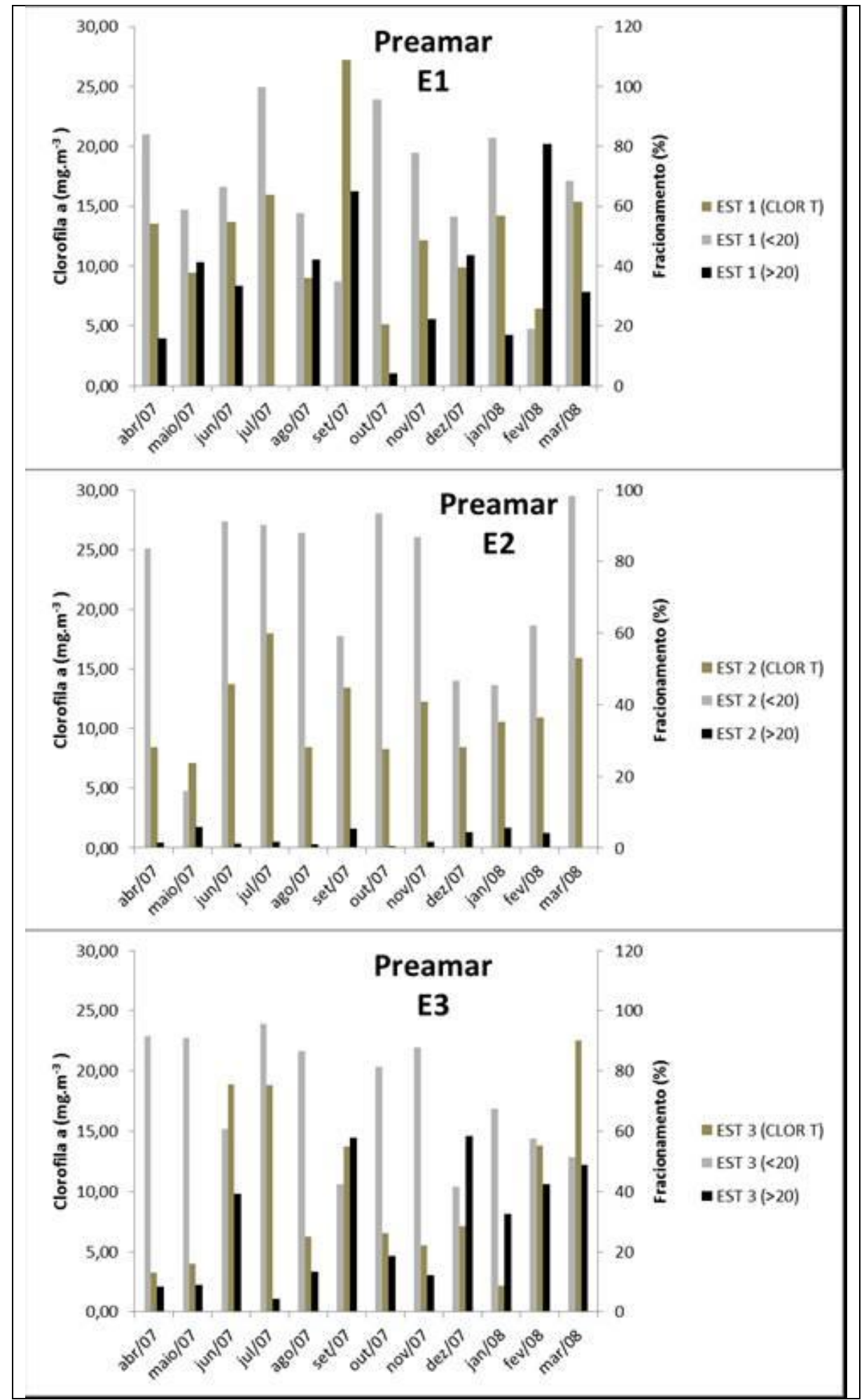

Figura 9 - Clorofila a em cada estação, em preamar (PM)

\section{- Análise dos componentes principais - ACP} 10)

Os dois fatores explicaram 45,53\% das variações dos dados. Com r=0,76. (Tab. 1) (Fig.

O Fator 1 explicou $30,25 \%$ da variação, estando a salinidade diretamente correlacionada com o oxigênio dissolvido, $\mathrm{pH}$, altura da maré e inversamente correlacionada com $\mathrm{NH}_{3}, \mathrm{NO}_{2}$, $\mathrm{NO}_{3}, \mathrm{SiO}_{2}$ e clorofila $a$. 
OTSUKA, A. Y. Condições Ambientais do estuário do rio Botafogo (Itamaracá-Pernambuco-Brasil): clorofila a e algumas variáveis ambientais.

O Fator 2 explicou $15,28 \%$ da variação, associando positivamente a DBO com material particulado em suspensão, pluviometria e temperatura e negativamente com $\mathrm{PO}_{4}$, profundidade e Secchi.

Tabela 1 - Correlação da ACP

\begin{tabular}{l|c|c}
\hline Parâmetros & $\begin{array}{c}\text { Fator 1 } \\
(\mathbf{3 0 . 2 6 \%})\end{array}$ & $\begin{array}{c}\text { Fator 2 } \\
\mathbf{( 1 5 . 2 8 \%}\end{array}$ \\
\hline Sal. & 0.8815 & 0.2025 \\
\hline O.D. & 0.3602 & -0.2123 \\
\hline D.B.O. & -0.3207 & 0.3334 \\
\hline pH & 0.8256 & -0.0592 \\
\hline MPS & 0.2144 & 0.6429 \\
\hline NH $_{3}$ & -0.4295 & 0.3680 \\
\hline NO $_{2}$ & -0.8299 & 0.1228 \\
\hline NO $_{3}$ & -0.7750 & 0.1177 \\
\hline PO $_{4}$ & -0.1201 & -0.7639 \\
\hline SiO & \\
\hline Clorofila a & -0.8520 & -0.2423 \\
\hline Altura de maré & -0.2908 & 0.0614 \\
\hline Pluviometria & -0.3935 & 0.6718 \\
\hline Profundidade & 0.2166 & -0.3710 \\
\hline Secchi & -0.0734 & -0.5247 \\
\hline Temperatura & 0.0348 & 0.1267 \\
\hline & & 0.3736 \\
\hline
\end{tabular}

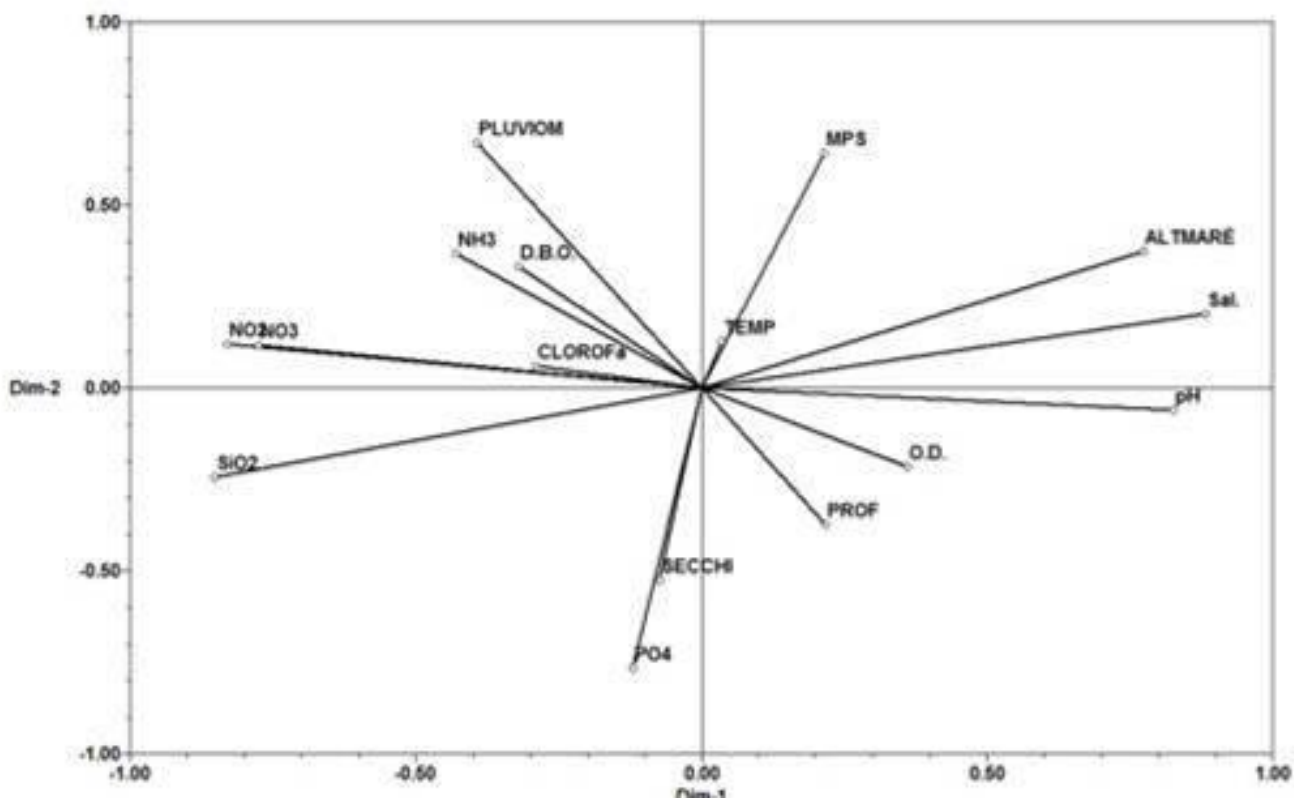

Figura 10 - Gráfico da ACP 
OTSUKA, A. Y. Condições Ambientais do estuário do rio Botafogo (Itamaracá-Pernambuco-Brasil): clorofila a e algumas variáveis ambientais.

Tabela 2 - Valores obtidos para os parâmetros no período seco e chuvoso, e teste estatístico.

\begin{tabular}{|c|c|c|c|c|c|c|c|c|c|c|c|}
\hline \multirow{2}{*}{ PARAMÊTROS } & \multicolumn{4}{|c|}{ ESTIAGEM } & \multicolumn{4}{|c|}{ CHUVOSo } & \multicolumn{3}{|c|}{$\begin{array}{c}\text { Teste Kruskal Wallis e } \\
\text { Anova um critério }\end{array}$} \\
\hline & Min. & Máx. & Média & $\mathrm{DP}$ & Min. & Máx. & Média & $\mathrm{DP}$ & Sazonal & Espacial & Maré \\
\hline Pluviosidade $(\mathrm{mm})$ & 8,5 & 81,7 & 35,9 & $\pm 24,53$ & 115,2 & 370,9 & 228,5 & $\pm 83,08$ & 0,00 & - & - \\
\hline Transparência (m) & 1 & 2,4 & 1,30 & $\pm 0,51$ & 0,3 & 1,45 & 0,97 & $\pm 0,42$ & 0,00 & 0,17 & - \\
\hline Temperatura $\left({ }^{\circ} \mathrm{C}\right)$ & 21,5 & 31,1 & 27,98 & $\pm 2,50$ & 25,3 & 39,8 & 28,24 & $\pm 2,56$ & 0,23 & 0,9 & 0,12 \\
\hline Salinidade & 9,69 & 36,34 & 26,77 & $\pm 7,85$ & 4,73 & 37,94 & 22,41 & $\pm 9,76$ & 0,00 & - & 0,00 \\
\hline $\begin{array}{l}\text { Ox.dissolvido(ml. } \mathrm{L}^{-} \\
\left.{ }^{1}\right)\end{array}$ & 2,91 & 6,05 & 4,40 & $\pm 0,77$ & 1,99 & 6,5 & 4,28 & $\pm 1,03$ & 0,35 & 0,79 & 0,02 \\
\hline $\mathrm{DBO}\left(\mathrm{mg} \cdot \mathrm{L}^{-1}\right)$ & 0,01 & 7,34 & 1,36 & $\pm 1,38$ & 0,21 & 3,77 & 2,18 & $\pm 1,14$ & 0,00 & 0,46 & 0,03 \\
\hline $\mathrm{pH}$ & 7,35 & 8,83 & 8,15 & $\pm 0,36$ & 6,92 & 8,68 & 7,98 & $\pm 0,40$ & 0,04 & - & 0,09 \\
\hline $\begin{array}{l}\text { Mat. Suspensão } \\
\left(\mathrm{mg} \cdot \mathrm{L}^{-1}\right)\end{array}$ & 2,00 & 45,00 & 28,23 & $\pm 12,66$ & 13,80 & 46,60 & 31,65 & $\pm 10,29$ & 0,30 & 0,11 & 0,00 \\
\hline Nitrito $\left(\mu \mathrm{mol} . \mathrm{L}^{-1}\right)$ & 0,00 & 0,28 & 0,07 & $\pm 0,08$ & 0,00 & 0,67 & 0,16 & $\pm 0,17$ & 0,01 & - & 0,00 \\
\hline Nitrato $\left(\mu \mathrm{mol} . \mathrm{L}^{-1}\right)$ & 0,22 & 14,70 & 2,85 & $\pm 3,53$ & 0,12 & 34,94 & 6,01 & $\pm 8,44$ & 0,04 & - & 0,00 \\
\hline Amônia ( $\mu \mathrm{mol} . \mathrm{L}^{-1)}$ & 0,00 & 0,17 & 0,02 & $\pm 0,03$ & 0,00 & 2,89 & 0,24 & $\pm 0,58$ & 0,00 & 0,76 & 0,12 \\
\hline Fosfato $\left(\mu \mathrm{mol} . \mathrm{L}^{-1}\right)$ & 0,22 & 1,38 & 0,70 & $\pm 0,26$ & 0,00 & 1,74 & 0,32 & $\pm 0,37$ & 0,00 & 0,47 & 0,00 \\
\hline Silicato $\left(\mu \mathrm{mol} . \mathrm{L}^{-1}\right)$ & 4,26 & 221,12 & 45,96 & $\pm 47,30$ & 3,10 & 178,07 & 60,60 & $\pm 45,78$ & 0,11 & - & 0,00 \\
\hline $\begin{array}{l}\text { Biomassa } \\
\text { fitoplanctônica } \\
\left(\mathrm{mg} \cdot \mathrm{m}^{-3)}\right.\end{array}$ & 2,15 & 22,40 & 9,21 & $\pm 5,41$ & 3,28 & 59,75 & 16,90 & $\pm 10,64$ & 0,00 & 0,63 & 0,51 \\
\hline
\end{tabular}

\section{DISCUSSÃO}

A pluviosidade tendeu a acompanhar a curva histórica, no entanto, ficou abaixo da média. Porém foi suficiente para modificar alguns parâmetros ambientais. Este fato já foi evidenciado em outros trabalhos e em outros estuários de Pernambuco, como Feitosa et al. (1999), Branco (2007) e Noriega et al. (2009) no estuário de Barra das Jangadas e na Bacia do Pina. Este padrão tem sido considerado freqüente para essa região.

Outra forçante física importante para o referido sistema foi os diferentes estágios de maré, que conseguiu interferir em vários parâmetros estudados. Em se tratando de uma área costeira sujeita ao efeito de uma mesomaré espera-se que haja influência dela sobre o sistema, aumentando as concentrações de clorofila, nutrientes, material particulado em suspensão.

A salinidade é um dos fatores mais importantes no sistema estuarino, servindo para limitar o início e término do referido sistema e ainda influenciando na distribuição dos organismos. No rio Botafogo a salinidade variou de oligohalino e euhalino. De acordo com Macêdo et al (1982) este estuário é do tipo estratificado.

O oxigênio dissolvido é um parâmetro químico muito utilizado para qualificar as condições ambientais de um determinado corpo d'água. Suas concentrações variam tanto em função da temperatura, salinidade e da atividade fotossintética. De acordo com Macêdo et al (1982), o estuário do rio Botafogo apresentou concentrações variadas de oxigênio dissolvido ao longo do ano, sendo que em baixa-mar oscilou desde zona poluída a semi-poluída e em preamar como zona supersaturada. Apesar de terem sido detectados níveis críticos de oxigênio dissolvido pelos autores acima, o efeito da circulação e dos processos de mistura sobre os movimentos e dispersão destas substâncias poluentes proporcionaram condições para uma rápida reciclagem dos recursos químicos e biológicos, ao contrario, nos dados atuais prevaleceu que o mesmo se apresentou como zona saturada (75 - 100\%), o que significa uma área bem suprida de oxigênio dissolvido, sendo um indicativo de um ambiente que ainda não está com excesso de matéria orgânica. Fato este confirmado pelos baixos níveis de DBO.

Os teores de nutrientes foram baixos, característicos de ambientes ainda isento ou pouco afetado pela ação antrópica. Os níveis de amônia e nitrito se encontraram dentro dos valores normais para a área estuarina. Caso semelhante ao encontrado por Honorato et al. (2009) no 
OTSUKA, A. Y. Condições Ambientais do estuário do rio Botafogo (Itamaracá-Pernambuco-Brasil): clorofila a e algumas variáveis ambientais.

rio Formoso, por Bastos et al. (2011) em Maracaípe, e diferente do que foi observado por Nascimento et al. (2003) que encontrou concentrações elevadas de nutrientes na Bacia do Pina.

A maioria dos nutrientes teve variação relacionada à sazonalidade. Os maiores valores de nitrito, nitrato e amônia foram encontrados no período chuvoso, diferente do silicato e fosfato que tiveram seus maiores valores no período de estiagem. Segundo Flores-Montes et al. (1998) no Complexo Estuarino de Itamaracá, os teores de nitrito e nitrato foram mais elevados no período chuvoso, enquanto a amônia e silicato tiveram maiores concentrações no período de estiagem. Passavante e Koening (1984), não encontraram uma variação sazonal dos nutrientes para esta mesma área.

O nitrato apresentou valores acima dos normais $\left(15 \mu \mathrm{mol} . \mathrm{L}^{-1}\right)$ na porção interna e no período chuvoso na baixa-mar, possivelmente em função da atividade agrícola na região.

O fosfato também apresenta maiores concentrações no período de estiagem. De acordo com Macedo et al (2000), as variações de fosfato ao longo do Canal de Santa Cruz são irregulares e as maiores concentrações foram registradas principalmente nas desembocaduras dos rios Botafogo e Congo. Outro fato interessante registrado pelos mesmos autores, é que as concentrações de fosfato na referida área sejam influenciadas diretamente pela existência de jazidas de fosfato na área costeira situada entre Olinda e Itamaracá, como também o relato de uma base de calcário Gramame como responsável por parte do suprimento natural de fósforo na área (Passavante, 1979; Macedo et al, 2000).

De acordo com Macêdo et al (1982), dados pretéritos da área informaram que os valores de nitrato e fosfato estiveram muito elevados na estação mais interna durante a baixa-mar no período chuvoso.

Dentro os nutrientes, o silicato foi o que apresentou as maiores concentrações, fato este já confirmado por Noriega et al. (2005) no sistema estuarino de Barra das Jangadas.

$\mathrm{Na}$ área estudada, os valores de clorofila a se encontram mais elevados no período chuvoso e no período de baixa-mar, esse fato pode ser justificado pelo aporte fluvial de nutrientes nesse período. Caso semelhante foi observado por Honorato (2003) no estuário do rio Formoso.

Os valores em média da biomassa fitoplanctônica estiveram abaixo de $20 \mathrm{mg} \cdot \mathrm{m}^{-3}$, ou seja, típico de áreas que não estão sofrendo ou sofrem relativamente pouco, com o lançamento de efluentes domésticos ou industriais no local, apesar da presença de fazendas de camarão neste estuário, o mesmo, nesse tempo de coleta, não afetou negativamente o ambiente. Esse perfil foi observado por e Bastos et al. (2011), Passavante et al.(2003). Ao contrário do encontrado por Feitosa et al. (1999) e Nascimento et al. (2003) na Bacia do Pina, um ambiente eutrofizado dados pretéritos levantados por Passavante e Koening (1984) verificaram que os teores médio de clorofila para o referido estuário foi de $6 \mathrm{mg} \cdot \mathrm{m}^{-3}$, comparando com os dados atuais, foi observado que houve um acréscimo considerável destes valores, superior a $100 \%$.

Em relação à contribuição das diferentes frações do fitoplâncton, a fração menor que 20 $\mu \mathrm{m}$ foi a que mais contribuiu com a produtividade do ecossistema, fato este também constatado por Feitosa et al. (1999) na Bacia do Pina e Greco et al. (2009) no estuário do rio Ariquindá.

O material particulado em suspensão foi típico de um rio litorâneo, ou seja, um rio curto, com baixa contribuição de material para a zona costeira. Comparando com trabalho de Passavante \& Koening (1984), o ambiente vem mantendo os mesmos valores de material particulado em suspensão na área.

\section{CONCLUSÃO}

Levando-se em conta o aumento considerável da biomassa fitoplanctônica em relação aos dados pretéritos, pode-se concluir que o ambiente estudado encontra-se em processo moderado de eutrofização.

\section{AGRADECIMENTOS}

Os autores agradecem ao Conselho Nacional de Pesquisa - CNPq pelo financiamento do projeto.

\section{REFERÊNCIAS BIBLIOGRÁFICAS}

APHA - American Public Health Association. Standard methods for the examination of water and wastewater. $20^{\text {th }}$ ed. Washington, $1998.1 .220 \mathrm{p}$. 
OTSUKA, A. Y. Condições Ambientais do estuário do rio Botafogo (Itamaracá-Pernambuco-Brasil): clorofila a e algumas variáveis ambientais.

BRANCO, E. S.; FEITOSA, F. A. N.; MONTES, M. J. F. Variação sazonal e espacial da biomassa fitoplanctônica relacionada com parâmetros hidrológicos no estuário de Barra de Jangadas (Jaboatão dos Guararapes - Pernambuco - Brasil). Tropical Oceanography, Recife: v. 30, n. 2, p. 79-96, 2002.

BRANCO, E. S. Influência das variáveis ambientais na comunidade fitoplanctônica estuarina. Recife: Ed. Universitária da UFPE. 2008, 266p.

BASTOS, R. B; FEITOSA, F. A. N.; KOENING, M. L.; MACHADO, R. C. A.; MUNIZ, K. Caracterização de uma zona costeira tropical (Ipojuca - Pernambuco - Brasil): produtividade fitoplanctônica e outras variáveis ambientais. Braz. J. Aquat. Sci. Technol, v.15, n. 1, p. 0110, 2011.

CAVALCANTI, L. B., MACEDO, S. J., PASSAVANTE, J. Z. O. Estudo ecológico da região de Itamaracá, Pernambuco - Brasil. XXI. Caracterização do Canal de Santa Cruz em função dos parâmetros físicos-químicos e pigmentos fotossintéticos. Trab. Oceanogr. Univ. Fed. PE., Recife, v. 16, p. 157-216, 1981.

CAVALCANTI, L. B. Estudo ecológico da região de Itamaracá, Pernambuco, Brasil. I - Nota Introdutória. Trab. Oceanogr. Univ. Fed. PE., Recife, v. 14, p. 55-64, 1979.

$\mathrm{CPRH}$. Diagnóstico socioambiental do litoral norte de Pernambuco. Recife: Agência Pernambucana de Meio Ambiente e Recursos Hídricos, 2001.

DiRetoria DE HIDROGRAFIA E NAVEGAÇÃO (DHN). Tábuas das marés. Porto do Recife (Estado de Pernambuco). Disponível em:

http://www.mar.mil.br/dhn/chm/tabuas/30645Set2011.htm Acessado em 27 março 2012.

ESKINAZI-LEÇA, E., FRANCA, L. M. B. F., MACEDO, S. J. Estudo ecológico da região de Itamaracá, Pernambuco - Brasil. XXIV. "Standing Stock" do fitoplâncton do estuário do rio Botafogo, durante janeiro a dezembro/75. Trab. Oceanogr. Univ. Fed. PE., Recife, v.18, p.153-192,1984.

ESKINAZI-LEÇA, E.; MACEDO, S. J.; PASSAVANTE, J. Z. de O. Estudo ecológico da região de Itamaracá, Pernambuco - Brasil. V. Composição e distribuição do microfitoplancton na região do Canal de Santa Cruz. Trab. Oceanogr. Univ. Fed. PE. Recife, v.18, p.153-192,1980.

ESKINAZI-LEÇA, E.; PASSAVANTE, J. Z. de O.; FRANÇA, L. M. Composição do microfitoplâncton do estuário do rio Iguarassu (Pernambuco). Bol. Inst. Oc. São Paulo, v.29, n.2, 1980.

FEITOSA, F. A. N.; NASCIMENTO, F. C. R.; COSTA, K. M. P. Distribuição espacial e temporal da biomassa fitoplanctônica rela- cionada com parâmetros hidrológicos na bacia do pina (Recife Pe). Trab. Oceanog. Univ. Fed. PE, Recife, v.27, n.2, p.1 - 13, 1999.

FLORES MONTES, M. J.; MACEDO, S .J.; KOENING, M L.; CORREIA, I. L. Variação nictimeral do fitoplâncton e elementos nutrientes no Canal de Santa Cruz, Itamaracá-PE-Brasil. Trab.

Oceanogr. Univ. Fed. PE. Recife, v.26, n.1, p.13-26, 1998.

GRASSHOFF, K.; EHRHARDT, M.; KREMLING, K. (Ed.) Methods of seawaters analysis, Verlag Chemie, $2^{a}$ edição. 419p. 1983.

GREGO, C. K. S.; FEITOSA, A. N.; SILVA, M. H.; CUNHA, M. G. G. S.; FILHO, G. A. N. Fitoplâncton do ecossistema estuarino do rio Ariquindá (Tamandaré, Pernambuco, Brasil): variáveis ambientais, biomassa e produtividade primária. Atlântica, Rio Grande, v.31, n.2, p.183 -198, 2009.

HONORATO, M. S. Fitoplâncton do estuário do rio Formoso (Rio Formoso, Pernambuco, Brasil). 2003. Dissertação Mestrado - Univ. Federal de Pernambuco. CTG. Oceanografia.p 131.

LACERDA, S. R.; KOENING, M. L.; NEUMANN-LEITÃO, S.; FLORES-MONTES, M. L. Phytoplankton nyctemereal variation at a tropical river estuary (Itamaracá - Pernambuco Brazil). Braz. J. Biol., v.64, n.1, p. 81 - 94, 2004. 
OTSUKA, A. Y. Condições Ambientais do estuário do rio Botafogo (Itamaracá-Pernambuco-Brasil): clorofila a e algumas variáveis ambientais.

LAMEPE/ITEP. Disponível em:

http://www.itep.br/index.php?option=com_content\&view=article\&id=877\&Itemid $=549$.

Acessado em 27 março 2012.

LEÃO, B. M.; PASSAVANTE, J. Z. de O.; SILVA-CUNHA, M. G. G.; SANTIAGO, M. F. Ecologia do microfitoplâncton do estuário do rio Iguarassu, PE, Brasil. Acta Bot. Bras. v.22, n.3, p. 711722, 2008.

MACEDO, S. J.; LIRA, M .E. F.; SILVA, J. E. Condições hidrológicas do Canal de Santa Cruz, Itamaracá, Pe. B. Rec. Nat., SUDENE. Recife, v.11, n1/2, p.55-92, 1973. In: BARROS, H.M.; ESKINAZI-LEÇA, E.; MACEDO, S.J.; LIMA, T. Gerenciamento Participativo de Estuários e Manguezais. Recife: Ed. Universitária da UFPE. Pg. 7-25., 2000.

MACEDO, S. J.; MELO, H. N. S.; COSTA, K. M. P. Estudos Ecológicos da Região de Itamaracá Pernambuco - Brasil. XXIII. Condições hidrológicas do estuário do rio Botafogo. Trab.

Oceanogr. Univ. Fed. PE., Recife, v.17, p.81-122, 1982.

MACEDO, S. J.; KOENING, M. L.; FILHO, A. L. V. Aspectos hidrológicos e fitoplanctônicos em viveiro estuarino (Itamaracá - Brasil). Trab. Oceanogr. Univ. Fed. PE., Recife, v.20, p. 99$124,1987 / 89$

MELO, P. A. M. C.; NEUMANN-LEITÃO, S.; GUSMÃO, L. M. O.; PORTO NETO, F. F. Variação nictemeral do macrozooplâncton na Barra Orange - Canal de Santa Cruz, estado de Pernambuco (Brasil). Rev. Bras. Enga. Pesca v.3, n.2, 2008

MOURA, A. R. L. U.; CANDEIAS, A.L.B. Uso de geotecnologias para o gerenciamento ambiental dos manguezais do sistema estuarino de Itamaracá - PE. Anais XV Simpósio Brasileiro de Sensoriamento Remoto - SBSR, Curitiba, PR, 2011.

MOURA, A. N.; PASSAVANTE, J. Z. de O. Variação sazonal da produção de algas perifíticas nos estuários dos rios Paripe e Igarassu, localizados ao sul do Canal de Santa Cruz (Pernambuco, Brasil). Rev. Bras. de Biociênc. v.8, 2003.

NASCIMENTO, F. C. R.; MUNIZ, K.; FEITOSA, F. A. N.; ARAUJO, J. P.; SILVA, R. M. S.; SILVA, G. S.; MONTES, M. J. F. Disponibilidade nutricional da bacia do Pina e rio Tejipió (Recife - PE Brasil) em relação aos nutrientes e biomassa primária (Setembro/2000). Tropical

Oceanography, Recife: v. 31, n.2, p. 149-169, 2003.

NORIEGA, C. E. D.;COSTA, K. M. P.; FEITOSA, F. A. N.; MONTES, M. J. F.; GREGO, C. K. S.; SOARES, G. S. S.; SILVA, H. P. Distribuição espacial da biomassa fitoplanctônica e sua relação com os sais nutrientes, no sistema estuarino de Barra das Jangadas (Pernambuco - Brasil).

Arquivos de Ciência do Mar. Fortaleza. v. 38: p. 5-18. 2005.

NORIEGA, C. E.; MUNIZ, K.; FLORES - MONTES, M. J.; MACEDO, S. J.; ARAUJO, M.; FEITOSA, F. A. N.; LACERDA, S. R. Séries temporales de variables hidrobiológicas en um estuário tropical (Brasil). Revista de Biologia Marina y Oceanografia, v 44, n. 1, p93-108. 2009.

ODUM, E. P Fundamentos de ecologia. Thonsom Learning, p.612, 2007.

PARANAGUÁ, M. N., NASCIMENTO, D. A., MACEDO, S. J. Estudo ecológico da região de Itamaracá, Pernambuco, Brasil. II. Distribuição do zooplâncton no estuário do rio Igarassu (1). Trab. Oceanogr. Univ. Fed. PE., Recife, v.14, p.65-92, 1979.

PARSONS, T. R.; STRICKLAND, J. D. H. Discussion of spectrophometria determination of marine-plant pigments, with revised equations for ascertaining clorophyll $a$ and carotenoids.

Journal of Marine Research, New Haven, v. 21, n. 3, 1963, p. 155-163.

PASSAVANTE, J. Z. de O. Primary production of phytoplankton from santa cruz channel (Brazil). Trab. Oceanogr.Univ.Fed.PE., Recife, v. 20, p.155-172, 1987/89.

PASSAVANTE, J. Z. de O. Estudo ecológico da região de Itamaracá, Pernambuco - Brasil. XIX. Biomassa do nano e microfitoplâncton do Canal de Santa Cruz. Trab. Oceanogr. Univ. Fed. PE., Recife, v. 16, p.105-156, 1981. 
PASSAVANTE, J. Z. de O.; KOENING, M. L. Estudo ecológico da região de Itamaracá, Pernambuco - Brasil. Xxvi. Clorofila a e material em suspensão no estuário do rio Botafogo.

Trab. Oceanogr. Univ. Fed. PE., Recife, v. 18, p. 207-230,1984.

PASSAVANTE, J. Z. O.; FEITOSA, F. A. N.; MACEDO, S. J.; ARAGÃO, J. O. R.; LEITÃO, S. N.; LINS, I.C. Produção, biomassa fitoplanctônica, climatologia e hidrologia do estuário do rio Botafogo, Itapissuma, Pernambuco. Bol. Téc. Cient. do Cepene, v. p. 2003

PLATT, T.; D. V SUBBA RAO; B IRWING. Photosynthesis of picoplankton in the oligotrophic ocean. Nature, v.301, p. 702-704. 1983.

SANTOS, T. G.; GUSMÃO, L. M. O.; NEUMANN-LEITÃO, S.; CUNHA, A. G. Zooplâncton como indicador biológico da qualidade ambiental nos estuários dos rios Carrapicho e Botafogo, Itamaracá - PE. Rev. Bras. Enga. Pesca v.4, n.1, 2009.

SANTOS-FERNANDES, T. L.; KOENING, M. L.; PASSAVANTE, J. Z. de O. Fitoplâncton do Estuário de Jaguaribe, Itamaracá, Pernambuco. Rev. Bio. Aq. Trop., Natal, v.10,, 2000, p.43-69.

SANTOS-FERNANDES, T. L.; PASSAVANTE, J. Z. de O.; KOENING, M. L.;MACEDO,S. J. Fitoplâncton do estuário do rio Jaguaribe, (Itamaracá, Pernambuco, Brasil): Biomassa. Trab. Oceanogr. Univ. Fed. PE., Recife, v. 26, n.2, p. 1-18, 1998.

SANTOS, T. G.; BEZERRA-JUNIOR, J. L.; COSTA, K. M. P.; FEITOSA, F. A. N. Dinâmica da biomassa fitoplanctônica e variáveis ambientais em um estuário tropical (Bacia do Pina, Recife, PE). Rev. Bras. Enga. Pesca v.4, n.1, 2009.

SILVA, L. A. de. Sedimentologia do Canal de Santa Cruz - Ilha de Itamaracá - PE. Dissertação (mestrado) - Universidade Federal de Pernambuco. 96 p. Recife, 2004.

SOARES, C. M. A. Estudo ecológico da região de Itamaracá, Pernambuco, Brasil. III. Anfípodos das famílias Talitridae e Ampithoidae. Trab. Oceanogr. Univ. Fed. PE., Recife,v. 14, n.93-104, 1979.

STRICKLAND, J. D. H.; PARSONS, T. R. A pratical handbook of seawaters analysis. Bulletin Fisheeries Research Board of Canada, Ottawa, v. 167, p. 207-211. 1972.

TORRES, F. T. P.; MACHADO, P. J. O. Introdução à Climatologia. Ed. Cengage Learning, São Paulo, 2011.

UNESCO. Determination of photosynthetic pigments in sea waters. Report of SCOR/UNESCO working group 17 with meat from 4 to 6 June 1964. Paris, (Monographys on Oceanology Methodology). 66 p. 1966

UNESCO. International Oceanographic Table. Great Britain Wormly 2, 141 p. 1973. 